\title{
¿Una «tercera vía» en el constitucionalismo? Comentario a Albert Noguera, La ideología de la soberanía. Hacia una reconstrucción emancipadora del constitucionalismo*
}

(2019) Trotta

Madrid, 168 pp.

\author{
Ricardo Cueva Fernández \\ Universidad Autónoma de Madrid \\ ORCID ID 0000-0003-2629-4652 \\ ricardo.cueva@uam.es
}

\section{Cita recomendada:}

Cueva Fernández, R. (2020). ¿Una «tercera vía» en el constitucionalismo? Comentario a Albert Noguera, La ideología de la soberanía. Hacia una reconstrucción emancipadora del constitucionalismo. Eunomía. Revista en Cultura de la Legalidad, 19, pp. 545-551.

doi: https://doi.org/10.20318/eunomia.2020.5729

Recibido / received: 12/08/2020

Es adecuado, pienso, dar la bienvenida a obras sobre filosofía jurídica que pretendan buscar nuevos enfoques para la disciplina y que muestren una cierta curiosidad por encontrar vías innovadoras para su desarrollo. Al respecto, el trabajo de Noguera parece transitar esta senda y no podemos por menos que congratularnos de ello. La acogida, al mismo tiempo, por la editorial Trotta, de un volumen de estas características, y corriendo asimismo cierto riesgo de desatención, me han conducido a colaborar con estas breves líneas en la sección Book Forum de la revista Eunomía, a la cual aprovecho para felicitar por su obtención de un merecido reconocimiento en las evaluaciones académicas.

En primer lugar, me parece conveniente señalar que me siento claramente cercano de una pretensión medular en el trabajo de Noguera, sin duda: la de interesarme por el «complejo campo de lucha de los derechos en el que construir nuestra dignidad individual y colectiva» (Noguera, 2019, p. 31). Dicho esto, hay que

\footnotetext{
* Este texto se enmarca dentro del proyecto SI1-PJI-2019-00474 (BICOM), de la Convocatoria 2019 de ayudas a Proyectos de I+D para jóvenes investigadores de la Universidad Autónoma de Madrid, financiada por la propia UAM y la Comunidad de Madrid.
} 
señalar que resulta difícil saber si el autor ha conseguido contribuir a ello con su volumen. Lo siguiente es un intento de buscar las claves de su reflexión y aportar otras meditaciones propias que sirvan para el debate.

Noguera empieza jugando fuerte en su primera página: «definimos modo de producción social como la unidad orgánica entre una forma de organización de las relaciones socioeconómicas (condición material) y una determinada subjetividad que legitima la primera (condición ideológica), conformando una forma histórico-concreta de sociedad». Es más, el autor piensa que «la noción moderna de soberanía operó durante mucho tiempo como modo de producción social de la Modernidad en tanto que actuaba como forma de organización socioeconómica además de ideología de legitimación de esta» (Noguera, 2019, p. 13). A continuación, y tras un breve excurso histórico, el autor insiste en lo que va a ser su centro de atención: «la noción contractualista moderna de soberanía opera como un nuevo modo de producción social en cuyo interior se dan las condiciones materiales y subjetivas de producciónreproducción del capitalismo» (Noguera, 2019, p. 22; los subrayados son propios, de aquí en adelante).

El embate, como se apunta, resulta así sumamente ambicioso (y repleto de vocablos compuestos). El lenguaje utilizado parece aproximarnos a algún tipo de elaboración de una teoría crítica sobre el Derecho, y acude a la noción de ideología bajo ciertos ropajes que parecen tomarse prestados del marxismo. El cometido que Noguera se propone es el de «desenmascarar» la soberanía. Y para ello, y desde un primer momento, derriba de un plumazo todas las teorías contractualistas típicas que llevan décadas orbitando alrededor de las teorías de la justicia, incluido J. Rawls (1971). En cualquier caso, «somos cautivos de una ideología de la soberanía moderna según la cual el orden coherente solo puede tener un único núcleo organizador» (Noguera, 2019, p. 24). El enemigo a batir es «la noción contractualista», de modo que la distinción entre contrato y pacto, tan útil a otros, no parece interesarle a Noguera. La forma de atacar aquélla es adoptar, así, la fórmula del «modo de producción social», cuyo significado, y esto a nadie se le puede escapar, no se corresponde con la expresión semejante de Marx (1975 [1859]), de muy distinto contenido. Aquélla se refiere directamente a un concepto político, e incluso constitucional, como es la «soberanía».

Hasta ahí hay una declaración de intenciones claramente honesta de Noguera y de lo que se propone y por qué caminos quiere discurrir: los de esquivar, a toda costa, las teorías quizás más en boga hoy acerca de la justicia. Para ello, asimismo, pronto advertimos que pretende sumergirnos en una literatura variada, dispar, que abarca varias disciplinas. Sus apuntes iniciales constan de la indicación de que en nuestras sociedades existiría «una fragmentación de los ejes de desigualdad y la visibilidad de nuevos grupos en situación de vulnerabilidad o pobreza», "en condiciones de no derechos o derechos más limitados que los ciudadanos corrientes» (Noguera, 2019, p. 23). Este seccionamiento conduce a Noguera a acudir a N. Luhmann (Noguera, 2019, pp. 24-25) para hallar lo que sería una adecuada explicación sobre la «diferenciación funcional con lógicas de organización interna propias [...] cuya interacción hace que los cambios en cada una de ellas afecten al sistema completo» (Noguera, 2019, p. 25).

Pero entonces, la pregunta que uno se hace es la de si hay sistema o no. $\mathrm{O}$, al menos, si existe algún conjunto social discernible al que someter al análisis. ¿Qué opina al respecto el autor? No parece que acepte su posibilidad; realmente, y a continuación, su rechazo resulta manifiesto: lo que hay es «una realidad policéntrica con la coexistencia de lógicas de organización estructural y superestructural de distintas épocas históricas, en las que el Estado tan solo es una de las diferentes 
configuraciones organizacionales epocales que se dan en ella». La operación aquí es clara: Noguera intenta extender esa percepción de «fragmentación» hasta hacerla imposible de medir, inabarcable. Si no acabamos de definir o concretar etapas, fases, o predominios que se sucedan en el tiempo, tampoco podremos obtener una unidad (y menos aún "orgánica», desde luego). Los saltos que reproduce el autor inmediatamente después, de las enclosures al G-7, parecen abundar en la misma idea (Noguera, 2019, pp. 26-27).

Sea como fuere, Noguera distingue tres superposiciones (algo a lo que recurre a menudo en el libro) de lo que denomina "espacio-tiempo histórico» (liberal, posliberal y preliberal), inclinándose claramente por el último: un ámbito (al ser tiempo y espacio a la vez, y también de forma que atraviesa todo hasta hoy, no sé de qué otra manera denominarlo) en donde existiría "una relación práctico-económica igualitaria o de reciprocidad en la que los miembros de la comunidad participan y se atribuyen equitativamente los beneficios de la producción y el intercambio, sin que existan ricos ni pobres». Asoma aquí, sin duda, una visión algo idílica de esas sociedades que Noguera acaba por apuntar que son «arcaicas y preindustriales» (Noguera, 2019, p. 26: ¿comunismo «primitivo», puesto que «preliberal»?), y en donde «el excedente es gestionado en común con vista a la producción, reproducción y crecimiento de la vida en comunidad». Pero, ¿qué producción? ¿De mera subsistencia? ¿Qué tipo de crecimiento, entonces? ¿Qué reproducción y de quién? Sorprende que, además de no contestar estas importantes preguntas, Noguera tampoco acuda al verter sus afirmaciones al respaldo de algún estudio de carácter antropológico, siquiera de los clásicos. Al menos Morgan (1985 [1877]) o Engels (2017 [1884]) ofrecian detalles, por ásperos que fuesen.

Sin abundar en este tema, sin embargo, interesa subrayar que, según el mismo autor, en nuestras sociedades estarían en tensión «tres espacios-tiempo históricos (liberal, posliberal y preliberal) con estructuras (sistema económico) y superestructuras jurídico-políticas (autoridades, formas de juridicidad y legitimidades) diferentes». Sus contornos no quedan demasiado definidos, pero baste saber que en el primero la autoridad ha sido (y es, recordemos que las tres formas se reproducen simultáneamente hoy) el Estado, en el segundo reside en organismos técnicos, internacionales y del sector financiero, y en el tercero es «comunitaria» (Noguera, 2019, p. 25: sin que Noguera acabe de concretar tampoco en qué consiste esta característica, insisto). Retengamos su aportación, para recuperarla un poco más tarde en estas líneas, porque el esquema tripartito se reitera en varias ocasiones de forma correlativa. Pero ya vamos adivinando uno de los pronunciamientos básicos del texto, si no el central. $Y$ es que su autor mezcla valoraciones propias, algo embozadas, pero fáciles de detectar, con otras afirmaciones de carácter «sociológico».

Tras explicar la aparición del mercado en la teoría política y social del siglo XVIII (Mandeville, 2004 [1714], Smith, 1983 [1776]), y aludiendo al esquema habitual que utilizaran los ilustrados escoceses (Wences, 2009, p. 160-162) y luego Hegel para separar la sociedad civil del Estado (Hegel, 2017 [1820], §§ 182-256 y 261, y est. prelim., pp. xxi-xxxiii), Noguera acaba sosteniendo que «tanto la socialdemocracia como el comunismo oficial pasaron a ser sinónimo de la defensa y promoción del intervencionismo de Estado como mecanismo desmercantilizador enfrentado a la sociedad-mercado» (Noguera, 2019, p. 39). El autor, claro es, rechaza esta dicotomía (Noguera, 2019, p. 41), pero de momento no indica alternativa alguna. Simplemente, apunta que «la evolución reciente del capitalismo ha llevado a una transformación de la naturaleza, objetivos y funciones del Estado que implica una complejización del campo de lucha de los derechos, dejando atrás la representación de este como dialéctica binaria y creando la necesidad de pasar a entenderlo como dialéctica 
compleja o de triple eje». Señala, asimismo, que el estado social del siglo XX asumía tres responsabilidades: la de garantía (asegurar derecho, servicios o prestaciones), la de cumplimiento o ejecución (realización efectiva de esas tareas, servicios o prestaciones) y la financiación (cobertura económica de todos ellos).

Sin entrar ahora en si esta última división (de nuevo tripartita) es correcta (parece que la segunda responsabilidad es sospechosamente parecida a la primera), o si resulta legítima la utilización del término "dialéctica» en los múltiples sentidos prescritos, sí hay que subrayar que inmediatamente después Noguera indica que el Estado ya no desempeña aquellos papeles mencionados. Pero, atención, porque introduce una locución imperativa de una manera algo extraña, dados los presupuestos de los que decía partir antes: «en esta coyuntura [¿cuál, originada por quién, con qué rasgos?] de pérdida de recursos y posiciones de titularidad y dominio sobre múltiples espacios y bienes, el Estado debe replegarse a otras posiciones estratégicas y desde ellas desarrollar otro tipo de actividad, transformando su naturaleza. El Estado debe asumir el reto de mantener los fines sin disponer de los medios, lo que obliga a una desagregación de responsabilidades». ¿Quién hace que eso deba ser así? De momento el autor rehúye una respuesta más concreta. Y por tanto parece aplazar la solución al problema que plantea. Lo malo es que lo va a acabar haciendo de manera indefinida. Lo que le importa es indicar que hay una maldita "dialéctica binaria», que resulta rechazable porque se empecina en un supuesto enfrentamiento Estado-sociedad 0 , si se quiere, Estado-mercado, inadecuado y falaz (otra «ideología», pues, que formaría parte de la «esfera mental de gran parte de las izquierdas», Noguera, 2019, p. 45).

Y es que la solución vendría de «considerar el campo de la lucha de [no por] los derechos como un campo donde operan tres esferas. El Estado como espacio de lo público, la sociedad como espacio de lo privado y la sociedad como espacio del procomún o de relaciones colaborativas y solidarias generadoras de igualdad», para añadir, inmediatamente a continuación, de manera sorprendente y sin mediar explicación previa, «que la desagregación de funciones del Estado a favor de la sociedad [¿no ha dicho que esa división es falaz?] puede entenderse como proceso de privatización generador de desigualdad, pero también como proceso de comunitarización generador de solidaridad e igualdad» (Noguera, 2019, p. 45).

La clave del trabajo aparece ya por fin aquí. Ante el retroceso del Estado en diversos sectores, la respuesta «para construir nuevas formas de dignidad» (Noguera, 2019 , p. 45) es «comunitarizar». Una operación que entiende Noguera que se estaría produciendo como hecho social (su alusión a las ocupaciones de tierras o viviendas así lo indica), pero que, además, se hallaría respaldado normativamente, puesto que es la alternativa para construir la dignidad. «Ante la inevitabilidad [de ahí lo de «debe», imaginamos] de un cada vez mayor repliegue garantista neoliberal, la extensión de estas formas colaborativas en el espacio del procomún será, en un futuro próximo, la única alternativa para la garantía de los derechos para amplios sectores de las clases populares que no puedan acceder al mercado. De ahí la importancia que el espacio del procomún cooperativo acabará teniendo para las clases populares a corto-medio plazo» (Noguera, 2019, p. 47).

Hasta aquí, el autor se pronuncia de una manera crítica que nos recuerda indudablemente a numerosos otros en búsqueda de modelos sociales alternativos. En realidad, mucho más a los socialistas utópicos o a los cooperativistas que a los pensadores del socialismo científico. Esto lo muestra a las claras también su asunción de un «pluralismo económico» (Noguera, 2019, p. 146) incompatible con propuestas de planificación o intervención fuerte (democráticas o no), o su señalamiento de, nada menos, que la existencia de varios «modos de producción» simultáneos en una misma 
realidad actual (Noguera, 2019, p. 136). En este, último aspecto, ¿de qué le vale acudir al concepto de plusvalía, precisamente el término unificador que nos permitiría hablar de modo de producción (capitalista)? En efecto, Noguera aboga por «estructuras de organización de lo colectivo, de distinta naturaleza, que ocupen y luchen por disputar cuotas de plusvalía en los distintos ejes del campo de lucha de los derechos de dialéctica compleja empezando a desarrollar prácticas alternativas transformadoras», de acuerdo con lo que denomina una «activación de un proceso de dialéctica entre un Derecho constitucional menor de anticipación y de consumación» (Noguera, 2019, p. 123; el primero, representado por la Revolución francesa y de orientación individualista, y el segundo procedente de la «Revolución» Gloriosa inglesa y de fundamentación historicista). Lo que no se acaba de aclarar es, entonces cómo implementar esos «derechos» a los que Noguera gusta tanto citar una y otra vez. Y menos identificar aquellos «ejes» de los que habla.

Y es que hay un pequeño problema que el autor debe sortear a continuación. Su especialidad, pese a sus muchas y dispares lecturas (de Rosanvallon a De Cabo, de Maravall a Ostrom, de Ferrajoli a Emmanuel) se supone que es el Derecho constitucional, así que debe proponer algo más en su volumen, si no quiere convertirse en uno más de entre muchos (fuera del campo jurídico) que critican la involución neoliberal.

La tripartición volverá a reproducirse en el texto, pues, algo más tarde, pero, al menos bajo el refinamiento que supondría introducir tres categorías, a saber, «hiperconstitucionalismo» («fortalecimiento de la ideología de la soberanía», Noguera, 2019, p. 61), "posconstitucionalismo» («abolición de esa idea», Noguera, 2019, p. 79) y alterconstitucionalismo («redefinición de la ideología de la soberanía», Noguera, 2019, p. 101). Pero aquí ya el ataque no es frontal. Es más, la supuesta radicalidad de las propuestas anteriores choca con el intento de construcción constitucional que ahora desfila ante nosotros. Así, el alterconstitucionalismo sería, y sin temor al oxímoron, «a la vez, una hoja de ruta para la transición y un proyecto político-constitucional, que supera la antítesis reforma-revolución y la reconcilia en una estrategia de reformismo revolucionario». "Plantea un nuevo sistema de relaciones sociales, políticas, económicas y culturales anticapitalista, aunque construido desde el constitucionalismo».

Pero, ¿acaso no había dicho ya Noguera que la soberanía es una ideología? ¿Hay un constitucionalismo que no la presuponga? Pudiera ser. Pero, entonces, por qué tendríamos que limitarnos a «redefinirla»? ¿En qué consistiría aquél? El autor parece navegar ya aquí entre demasiadas ambigüedades, malamente solventadas mediante un recurso a la "dialéctica» poco excusable por reiterado y fácilmente mutable en su caso. Que la transformación social y económica «no es posible únicamente con el Estado y la ley» (Noguera, 2019, p. 103), ya no los han dicho muchos autores y autoras antes (Gramsci [1974] de una manera, Marx de otra, J. S. Mill [1965 (1859)] también, I. M. Young [1990]), pero el sostener que hace falta un nuevo reformismo («revolucionario», sic), «de sujeto, objeto y prácticas plurales» (Noguera, 2019, p. 103) parece añadir confusión a cualquier receta, ya que ni se considera a un sujeto individual moral indeterminado (universal, diríamos), ni tampoco a otro colectivo agrupado bajo un programa de acción política. ¿De quién habla exactamente Noguera? ¿Quiénes son las «clases populares» a las que aquí se refiere? ¿No es la «gente corriente» a la que arriba aludía? ¿Qué les une o distingue? ¿A quién o a quiénes habría que agrupar? ¿Con quién practicar la «hegemonía»? Los liberales a quienes critica al menos toman un marco moral de referencia enérgico para apuntalarse, y la «izquierda» de la que tan despectivamente habla, organizaciones y actuación políticas continuadas y coordinadas en el tiempo. Noguera emplea, en 
cambio, el término «diversidad» y lo identifica, lisa y llanamente, con el de la mulititud negriniana (Noguera, 2019, p. 136).

Es más, la «multifragmentación de las estructuras de explotación, desigualdad y exclusión, así como una multiactividad nómada de las fuerzas de trabajo y supervivencia que se expresa en la ya explicada complejización del campo de la lucha de los derechos» (Noguera, 2019, p. 104), en contra de lo afirmado por Noguera, no es nueva en absoluto (de hecho, el autor percibe numerosas «novedades» donde no hay tantas). Cierta atracción por enfoques posmodernos implica este tipo de aproximación, obviamente. Si sustituimos derechos por «reclamos», o reivindicaciones, a la manera de Laclau (La razón populista [Laclau, 2005]), la operación nos podría resultar familiar. Pero una perspectiva más apegada a la Historia serviría para descubrir que la fragmentación social que hoy nos parece tan grande en realidad ya existía en tiempos de la Revolución Industrial. Entonces, numerosas familias al completo tejían para propietarios de la industria en sus propias casas. La «precarización» era un fenómeno constante que recorría un mundo repleto de desposeídos de sus tierras, así como braceros, marineros y campesinos arrendatarios. Lo extraordinario de aquella situación es que pudieran engendrarse, muchas veces a pesar de la situación social poco propicia y de la represión de autoridades y jueces y tribunales, bastantes sindicatos, cooperativas, o partidos obreros, agrupaciones de jornaleros o centros de reunión. Y por supuesto, que sus demandas se articularan en el lenguaje de los derechos. En el fondo, en el estudio de Noguera hay una especie de retroceso: como el Estado está siendo tomado y asaltado por los adalides del capitalismo, retirémonos a nuestros rincones del «procomún», como cimarrones (Noguera, 2019, p. 72) escapados del esclavismo que sin embargo no pueden abolirlo, en un lugar donde parece haber horizontalidad sin democracia, cierta ilusión de satisfacer necesidades sin desarrollo alguno, o la protección del más débil sin instituciones sólidas que sobrepasen los meros poderes locales (Noguera, 2019, p. 127).

No quiero que se me malinterprete, sin embargo. El profesor Noguera ha sido guiado por una encomiable pretensión de buscar nuevos senderos para el Derecho constitucional. Sus mejores resultados, quizás, se encuentren en gran parte de la crítica a lo que denomina el hiperconstitucionalismo, que se hallaría bien representado por Ferrajoli, así como, sobre todo, la que vierte contra el posconstitucionalismo. El problema que subyace en el volumen es el de someter a términos precisos una inquietud elogiable que, sin embargo, malgasta parte de su fuerza intentando cohonestar una literatura demasiado heterogénea. Además, le persigue en ocasiones cierta manía, inteligible pero poco fiable, en la empresa que desea acometer; a saber, la de confundir variedad con pluralismo, y teoría solvente cohesiva con ideología hegemónica. La querencia por la dispersión en lugar de la unidad metodológica, por el comentario sociológico frente al diseño normativo, por la espontaneidad en la narración en vez de la inteligibilidad de las conclusiones. Se trata de afanes plausibles en ciertas dosis, sin duda, pero no conviene abusar de ellos o quizás el lector puede que ignore a qué nos estamos refiriendo.

\section{Bibliografía}

Engels, F. (2017 [1884]). El origen de la familia, de la propiedad privada y del Estado. Madrid: Akal.

Gramsci, A. (1974). Antología (M. Sacristán, ed. y trad.). Madrid: Siglo XXI.

Hegel, G. W. F. (2017 [1820]). Fundamentos de la filosofía del Derecho. Madrid: Tecnos. 
Laclau, E. (2005). La razón populista. Buenos Aires: Fondo de Cultura Económica. Mandeville, B (2004 [1714]). La fábula de las abejas. Ciudad de México: Fondo de Cultura Económica.

Marx, K. (1975 [1859]). Prólogo de la contribución de la economía política. En Obras escogidas de Marx y Engels (pp. 346-351). Madrid: Ayuso.

Mill, J. S. (1965 [1859]). De la libertad. Del gobierno representativo. La esclavitud femenina. Madrid: Tecnos.

Morgan, L. H. (1985 [1877]). Ancient Society. Tucson: University of Arizona Press.

Noguera, A. (2019). La ideología de la soberanía. Hacia una reconstrucción emancipadora del constitucionalismo. Madrid: Trotta.

Rawls, J. (1971). A Theory of Justice. Cambridge, Mass.: Harvard University Press.

Smith, A. (1983 [1776]). Investigación de la naturaleza y causas de la riqueza de las naciones, 3 vols. Barcelona: Orbis.

Wences, I. (2009). Hombre y sociedad en la llustración escocesa. Ciudad de México: Fontamara.

Young, I. M. (2000 [1990]). La justicia y la política de la diferencia. Madrid: Cátedra. 